\title{
AUDIOBOOK SEBAGAI MEDIA ALTERNATIF DALAM REVITALISASI MASATUA BALI
}

\author{
Oleh: I Gusti Ngurah Agung Wijaya Mahardika ${ }^{1}$
}

\begin{abstract}
The advancement of technology has brought changes in the use of Balinese language for the Balinese. The Balinese language has been set aside in numerous domains of life. To conserve and preserve the existence of Baline language, steps need to be taken in accommodating said advancement of technology to attract the younger generation interest. This paper discusses the idea to use audiobook as a medium to revitalize the masatua Bali (Balinese story telling) tradition as a form of language exposure to the young learners. The use of satua Baliaudiobook should follow the six principles of delivering audio materials and abide to the systematic steps of pre-listening, while listening, and post-listening steps. This steps would ensure the attainment of multiple benefits of the satua Baliaudiobook, namely, exposure of Balinese language to the young learners, fostering the noble values in satua Bali, and at the same time improving the quality of emotional relationship between the parents and the children
\end{abstract}

Key Word: Balinese Language, audiobook

\begin{abstract}
Abstrak
Kemajuan teknologi membawa perubahan dalam penggunaan bahasa Bali bagi orang Bali. Bahasa Bali mulai tergeser kedudukannya dalam berbagai domain kehidupan. Untuk mempertahankan dan melestarikan bahasa Bali, perlu dilakukan tindakan yang bisa mengakomodasi kemajuan teknologi sehingga menarik minat generasi muda. Makalah ini memaparkan ide untuk menggunakan audiobook sebagai media untuk membangkitkan kembali budaya masatua Bali sebagai bentuk pemaparan bahasa pada usia dini. Kegiatan pemutaran audiobooksatua Bali sebaiknya mengikuti enam prinsip penggunaan materi audio serta mengikuti langkah-langkah sistematis yang terdiri atas langkah pra mendengarkan, mendengarkan, dan pasca mendengarkan. Dengan langkah-langkah ini, kegiatan mendengarkan audiobook akan menghasilkan manfaat ganda yaitu memaparkan anak pada bahasa Bali, menanamkan nilai dan amanat mulia yang tersirat dalam satua Bali, sekaligus juga meningkatkan kualitas hubungan emosional antara ibu dan anak
\end{abstract}

Kata kunci: Bahasa Bali, audiobook

${ }^{1}$ I Gusti Ngurah Agung Wijaya Mahardika, S.Pd. M.Pd. dosen pada Jurusan Pendidikan Bahasa dan Sastra Agama, Institut Hindu Dharma Negeri Denpasar. 


\section{Latar Belakang}

Perubahan jaman serta kemajuan teknologi pada akhirnya akan membawa perubahan pada kebudayan suatu bangsa. Hal yang sama terjadi pada Bali dan kebudayannya. Dewasa ini banyak pergeseran budaya yang terjadi yang disebabkan oleh era globalisasi. Bahasa Bali serta penggunaan Bahasa Bali sebagai bagian dari budaya dimaksud, juga tidak luput dari perubahan dan pergeseran tersebut. Diakui atau tidak, bahasa Bali kini harus berjuang untuk tetap memiliki tempat di rumahnya sendiri. Karena terdapat kecenderungan menurunnya penggunaan Bahasa Bali terutama di kalangan generasi muda (Sidi, 2014:2). Generasi muda Bali semakin jarang menggunakan Bahasa Bali dalam pergaulan sehari-hari. Hal ini tentunya menyedihkan, karena Bahasa Bali adalah Bahasa ibu bagi generasi muda Bali yang lahir di Bali. Bahasa Bali bukanlah sekadar alat komunikasi antar individu dalam lingkup budaya dan geografis bali saja. Namun juga merupakan suatu bentuk identitas sosial bagi orang bali (Suarjana, 2007:72).

Dewasa ini posisi bahasa Balidi pulau Bali yang merupakan tujuan wisata harus berdampingan dengan Bahasa Indonesia dan jugabahasaasing lainnya. Hal ini menyebabkan dalam kehidupan sehari-hari bahasa Bali dipergunakan secara silih berganti dengan bahasa Indonesia dan bahasa asing. Fenomena ini bahkan sudah merambah ke dunia seni pertunjukkan seperti misalnya dilaporkan oleh (Dwijayanti, 2016). Dwijayanti menemukan bahwa petunjukkan kesenian Tektok yang dipentaskan di Ubud, yang dulunya menggunakan bahasa Bali, kini juga menggunakan bahasa asing yaitu bahasainggris untuk mengakomodasi parapenonton yang sebagian besar adalah tamu asing. Hal ini menunjukkan bahwa telah terjadi pergeseran bahasa yang disebabkan oleh faktor ekonomis.

Fenomena pergeseran penggunaan bahasa ini juga terjadi di ranah kehidupan sehari-hari. Mulai dari kehidupan di pasar sampai di percakapan di media sosial seperti aplikasi pesan instan Blackberry Messenger (BBM) (Welyantari, 2016). Hal ini sepertinya sangat disadari oleh masyarakat Bali sendiri. Kesadaran akan degradasi penggunaan bahasa Bali ini mendorong timbulnya tindakan koservasi bahasa dan budaya dalam berbagai bentuk dan ranah. Salah satu bentuk konservasi dimaksud adalah penyelenggaraan Internasional Festival of Balinese Language (IFBL) yang diprakarsai perupa terkenal Bali, Nyoman Gunarsa. Festival Bahasa Bali Internasional ini diadakan pada 8 Oktober - 9 Oktober 2013 dan bertujuan untuk memperkenalkan dan mengembangkan budaya Bali kepada dunia. Dalam festival tersebut diselenggarakan juga Lomba Baligraphy, yaitu lomba menulis kaligrafi dengan menggunakan huruf atau aksara Bali. Lomba ini merupakan usaha menyebarluaskan dan melestarikan huruf atau aksara Bali sekaligus juga menyampaikan pesan melalui Baligraphy yang dibuat oleh para peserta (Suwandayani, 2015).

Langkah lain yang juga harus dilakukan oleh pengguna bahasa Bali untuk melestarikan bahasa dan budaya Bali adalah dengan memperkenalkan bahasa Bali kepada anakanak Bali dalam usia sedini mungkin. Di jaman dahulu, pengenalan bahasa Bali dilakukan secara langsung, karena anak-anak Bali menggunakan dan menerima bahasa Bali dalam kehidupan sehari-hari. Namun kini anak-anak Bali tidak lagi menggunakan bahasa Bali secara eksklusif. Hal ini disebabkan oleh paparan bahasa lain seperti bahasa Indonesia dan bahasa asing di sekolha, di ranah pergaulan terutama di daerah urban, dan bahkan saat anaanak berbicara dengan orang tuanya. Kondisi dimana orang tua Bali menguasai lebih dari satu bahasa, membuat penggunaan bahasa selain bahasa Bali di rumah tangga menjadi semakin tinggi kekerapannya.

Penggunaan bahasa Indonesia dan bahasa asing di rumah tangga merupakan salah satu kondisi yang memiliki kontribusi besar dalam 
penurunan penggunaan bahasa Bali di kalangan anak-anak dan generasi muda Bali. Sudah sepatutnya orang tua Bali kembali menggalakkan penggunaan bahasa Bali di tingkat keluarga. Penggunaan bahasa Bali di rumah tangga tentunya tidak cukup hanya dengan percakapan harian saja, namun juga bahasa Bali perlu dosampaikan dalam bentuk sedemikian rupa, yang mampu menarik dan mempertahankan perhatiananak.

Salah satu cara untuk mengemas paparan bahasa Bali secara menarik adalah dengan menggunakan bahasa Bali saat bercerita, atau di Bali jamak disebut sebagai masatua. Di masalalu, saat pilihan hiburanuntuk anak masih terbatas, maka tuturan cerita orang tua dan orang yang dituakan adalah satu-satunyapilihan hiburan bagi anak. Ini menyebabkan anak anak mendapat paparan langsung dari bahasa ibunya, di konteks Bali, bahasa Bali. Namun seiring dengan berjalannyawaktu dan kemajuanjaman. Posisi orang tua sebagai sumber cerita dan peran satua Bali sebagai hiburan secara perlahan digantikan oleh bentuk hiburan modern. Diawali dengan masuknyatelevisi, yang memberikan tidak saja paparan suara namun juga tampilan visual yang memukau dengan warna-warna cerah dan menarik hati.

Dengan kemajuan pesat pada layanan satelit, posisi televisi analog kemudian juga perlahan ditinggalkan dan digantikan oleh kehadiran televisi digitaldenganlayanan jejaring kabel (cable network). Dengan hadirnya jejaring kabel dan TV berlangganan, anak-anak semakin dimajakan dengan kehadiran televise yang memiliki dedicated broadcast atau siaran khusus, dimana banyak stasiun televise yang hanya menyiarkan satu jenis materi saja, mulai dari materi kartun anak, serial komedi, kuliner, hingga saluran televise religious. Anak-anak yang sudah kecanduan saluran kartun, akan menghabiskan waktu mereka terpana di depan televisi, yang menyiarkan kartun anak selama 24 jam non-stop selama 7 hari seminggu.
Perkembangan terakhir dalam dunia hiburan rumahan adalah Internet TV atau TVOD atau Television on demand. Televisi internet dan TVOD bekerja dengan sistem streaming dimana tayangan acara televisi tidak lagi diatur secara baku oleh stasiun penyiar, pelanggan diberikan kebebasan untuk memilih jenis tayangan apa yang akan ditontonnya dengan sesuka hati. Jika pada awal era televisi anak-anak dapat melihat tayangan televisi dengan segala warna yang cerah, di era TV Kabel, anak dapat menonton acara kartun seharian, dan kini di era televisi internet anak dapatmemilihfilmkartun yang merekainginkan dengan tidak terikat pada jadwal penayangannya. Semua pilihan hiburan ini akhirnya semakin menjauhkan anak-anak Bali dari masatua, bahasa Bali, dan pesan-pesan mulia dalam satua Bali warisan leluhur mereka.

Untuk mengatasi permasalahan ini diperlukan langkah-langkah baru yang mampu menjembatani tujuan dan keadaan saat ini. Langkah ini jugaharus berbasis teknologi yang memudahkan serta menarik perhatian anakanak. Salah satu langkah yang bisa menjadi alternative dalam masatua, dengan tetap menyampaikan esensi dari masatua itu, dan berbasis teknologi adalah penggunaan audiobook dalam masatua. Audiobook sebagai bentuk modern dari buku bukanlah hal yang asing bagi pecinta cerita dan juga teknologi. Menilik keadaan terkini, audiobook sepertinya layak dipertimbangkan sebagai sarana masatua. Pada bagian berikutnya dari paper ini, akan diuraikan lebih lanjut mengenai audiobook serta strategi penggunaannya.

\section{Pembahasan}

\subsection{Audio book}

Audiobook merupakan bentuk alternatif dari wacana tertulis dan tercetak. Media audiobook sejatinya dikembangkan untuk memperkaya khazanah media yang dapat 
diakses oleh para penikmat buku. Awalnya audiobook dibuat untuk membantu para penikmat buku untuk bisa menikmati buku meski dalam keadaaan yang tidak memungkinkan mereka untuk membaca, misalnya saat sedang menyetir, berkendara, atau bahkan saat sedang mengerjakan suatu pekerjaan lain. Dalam perkembangannya, audiobook juga digunakan secara efektif dalam proses belajar mengajar.

Sejarah audiobook sendiri berawal dari penciptaan phonograph oleh Thomas Alva Edison pada tahun 1877. Saat itu phonograph mulai digunakan untuk merekam suara terutama music dan lagu. Belakangan, pada tahun 1930 pemerintahAmerika Serikat melalui The Library of Conggress bekerjasama dengan American Federation for the Blind untuk melakukan pengembangan audiobook yang bernama The Talking Book Programs yang bertujuan untuk mengembangkan audiobook bagi para veteran yang terluka di perang duni pertama dan juga orang-orang tunanetra pada umumnya.

Pada tahun 1970, seiring dengan penciptaan kaset audio, maka popularitas audiobook di amerika serikat semakin meningkat. Audiobook kemudian mulai merambah ke sekolah-sekolah dan digunakan sebagai materi pelajaran, tidak saja untuk siswa tunanetra namun juga untuk siswa awas (melihat). Semenjak saat itu, dengan dibantu oleh teknologi yang berkembang dengan sangat pesat, audiobook seringkali menjadi pilihan orang saat mereka membutuhkan informasi dari buku atau sekadar ingin membaca buku dan menikmati isinya sembari tetap bisa melakukan pekerjaan atau aktivitas lain.

Audiobook dan penggunaan audiobook untuk menyampaikan informasi atau cerita, memiliki beberapa kelebihan. Wolfson (2008) menemuka bahwa audiobook berperan penting dalam proses belajar siswa. Hal ini disebabkan oleh karena siswa dapat berkonsentrasi penuh pada makna kata dan mengeplorasi makna tersirat dalam setiap baris kalimat dalam audiobook yang mereka dengarkan. Sama seperti buku cetakan, audiobook juga merangsang siswa untuk menghubungkan pengetahuan terdahulu (prior knowledge) mereka dengan kata-kata atau informasi yang mereka dengar. Lebih jauh lagi, audiobook memberikan kesempatan untuk anak untuk mendapat pengalaman yang lebih bermakna dan konkrit jika dibandingkan dengan buku cetakan. Hal ini didukung oleh pendapat Edgar Dale dalam teorinya yang dikenal dengan Kerucut Pengalaman (Cone of Experience. Teory Dale ini menyataan bahwa siswa mampu mengingat $20 \%$ dari informasi dalam bentuk suara yang mereka dengar, dibandingkan dengan 10\% dari teks yang mereka baca(Dale, 1969). Bagi siswa dengan modalitas belajar auditory, audiobook memiliki kelebihan tak terbantahkan jika dibandingkan dengan buku cetak, karena bagi mereka mendengarkan audiobook akan lebih menyenangkan dan efektif daripada membaca buku cetakan. Dengan audiobook siswa memiliki kebebasan untuk mengendalikan volume, repetisi kalimat, bahkan kini dengan kemajuan teknologi, kecepatan suara yang diperdengarkan. Dengan teknologi terkini, audiobook menawarkan lebih banyak lagi kelebihan disbanding buku cetakan. Audiobook masa kini sudah bisa memasukkan suara latar belakang, efek suara, dan dapat dibuat dengan suara berbeda untuk karakter berbeda atau situasi berbeda dalam setiap halnya. Satu hal yang bisa menjadi selling point dari audiobook disbanding buku cetakan adalah pembuatan audiobook yang sangat mudah disbanding dengan buku cetakan. Dengan menggunakan software pengolah suara yang dewasa ini banyak tersedia, audiobook dapat dibuat bahkan oleh orang dengan pengalaman minimal sekalipun.

Di bidang pendidikan, audiobook telah banyak digunakan semenjak tahun 1970 terutama di sekolah-sekolah di amerika serikat. Telah terdapat banyak bukti mengenai efektivitas dan manfaat audiobook untuk 
pengajaran dan kehidupan akademik pada umumnya. Goldsmith (2002) menuturkan hasil penelitiannya yang dilakukan di Berkeley High School, khususnya di sebuah grup belajar bahasa inggris yang bernama Earphone English. Grup Earphone English ini merupakan sebuah kelompok belajar bahasa inggris yang didesain oleh siswa dan ditujukan untuk siswa yang datang dari budaya yang tidak menggunakan bahasa inggris sebagai bahasa pertama. Sebagian besar pesertanya adalah siswaimigran yang membutuhkan bimbingan dalam penguasaan bahasa inggris. Para siswa ini datang ke grup Earphone English ini dan mulai belajar dengan mendengarkan pada sejumlah audiobook dengan topik-topik yang berbedabeda. Kemudian mereka akan mendiskusikan hasil pendengarannya dengan rekan-rekan sesama siswaimigran.

Goldsmith (2002) memulai proyek mendengarkan audiobook hanya dengan lima orang siswa imigran yang dating setiap jumat saat istirahat untuk membicarakan mengenai buku yang telah mereka baca. Perlahan jumlah siswa yang berminat membengkak menjadi 32 siswa level SMU dan 25 orang siswa level SMP. Dalam proyek ini Godsmith menemukan bahwa audiobook sangat berguna sebagai bahan bacaan untuk siswa dan bahkan memiliki nilai tambah yaitu berfungsi sebagai model pengucapan kata. Hal ini sangat menguntungkan untuk anak-anak yang sedang mempelajari bahasa asing. Dalam laporan Godsmith, audiobook berhasil meningkatkan kemampuan membaca pemahaman sang pengguna dan juga membangun kepercayaan diri sang pengguna saat berkomunikasi secara verbal.

Laporan dari Goldmisth ini membuka pintu pengetahuan baru, bahwa mendengarkan audiobook bahkan bisa lebih efektif dan memberikan nilai tambah bagi siswa. Karena selain membebaskan siswa dari bentuk tertulis dari sebuah bahasa atau kata, siswa mendapatkan pemodelan bahasa, kecepatan bicara, dan intonasi secar tidak sadar. Hal ini mendorong siswa berbicara lebih cepat, karena mereka dengan mudah menjiplak pengucapan kalimat-kalimat dalam audiobook yang mereka dengar.

\subsection{Pengembangan Audiobook}

Penelitian lain dari Ozgur dan Gurcan (2004) memberikan gambaran proses pengembangan audiobook bagi siswa tunanetra dan siswa awas yang bersekolah di Fakultas Pendidikan Terbuka di Universitas Anadolu, Turki. Ozgur dan Gurcan mengembangkan audiobook sejatinya untuk mengakomodasi kebutuhan siswa tunanetra di Fakultas Pendidikan Terbuka di Universitas Anadolu, Turki yang mengikuti program pendidikan jarak jauh yang mirip dengan skema pendidikan Universitas Terbuka di Indonesia. Format audiobook dipilih karena memberikan kemudahan yang luar biasa bagi siswa but ajika dibandingkan dengan buku cetakan. Mereka juga menjelaskan bahwa kemudahan pengembangan dan penggunaan merupakan alasan utama yang membuat mereka memilih fomat audiobook.

Dalam proses pengembangannya, audiobook dapat dibuat melalui 3 langkah sederhana yaitu 1) penulisan materi (drafting), 2) perekaman (recording) dan tahap finalisasi (finishing). Pada langkah pertama pengembangan audiobooksatua Bali, yang harus kita fikirkan dan siapkan adalah materi satua itu sendiri. Setelah mendapat materi satua yang tepat, kita juga harus mempertimbangkan target audience dari audiobook tersebut. Data target audience ini menentukan bentuk ujaran, pilhan kata, dan idiom-idiom yang dipakai dalam bercerita. Perlu kita pertimbangkan bahwa anak-anak yang masih berusia dini perlu mendapat masukan kalimat yang tidak terlalu berat, baik dari segi panjang kalimat maupun struktur gramatika. Demikian pula topik dan amanat dari satua perlu kita pilih agar sesuai dengan level psikologis dan kognitif target audience. Usia anak juga menentukan panjang 
audiobook yang akan kita buat, hal ini penting karena anak-anak kecil memiliki rentang konsentrasi yang jauh lebih pendek dari orang dewasa. Ozgur dan Gurcan menyarankan agar durasi setiap audiobook tidak melebihi 20 menit. Hal ini agar anak yang mendengarkan tidak bosan dan kehilangan daya tarik mereka.

Langkah kedua adalah perekaman atau recording. Dalam langkah ini hal utama yang dilakukan adalah perekaman pembacaan satua yang telah dipilih di tahap Penulisan Materi. Secara teknis, idealnya setiap karakter dalam sebuah cerita disuarakan oleh aktor atau talent yang berbeda. Demikian pula suara dari narrator utama, jika narasi cerita menggunakan sudut pandang orang ketiga. Namun jika terdapat keternatasam talent atau aktor pembaca, karakter suara dapat dirangkap oleh satu aktor selama sang aktor mampu membuat perbedaan warna dan karakteristik antara satu karakter dengan karakter lainnya.

Perekaman ini tidaklah membutuhkan alat khusus. Di jaman modern dengan akses teknologi saat ini perekaman dengan menggunakan alat-alat umumseperti laptop, microphone, dan bantuan perangkat lunak pengolah suara telah mampu menghasilkan kualitas rekaman audio yang dulu hanya bisa dilakukan pada studio music professional. Salah satu program atau perangkat lunak yang dapat dipakai untuk merekam sekaligus mengedit suara hasil rekaman dengan baik adalah aplikasi Adobe Audition. Semetara alat yang dipakai cukup hanya berupa laptop atau computer desktop yang terhubung dengan microphone.

Secara teknik, microphone diletakkan ditengah para pembaca atau aktor, dengan jarak antara aktor dengan microphone tidak berbeda. Kebutuhan berikutnya adalah tempat perekaman, tidak harus dilakukan di sebuah studiokedap suara, cukup dilakukan di ruangan yang tenang, yang tidak terganggu suara-suara seperti suara lalu lintas, desau angin, dan sejenisnya. Hal yang perlu diingat adalah bahwa para aktor telah membaca materi mereka dan telah membaca bersama aktor lainnya utnuk memastikan tidak ada kebingungan saat perekaman. Untuk itu penting diadakan gladi atau reaharsal sebelum perekaman dilakukan. Setelah materi terekam, maka langkah selanjutnya adalah adalah finalisasi atau finishing.

Langkah finalisasi adalah langkah terakhir dalam pengembangan audiobook dan juga merupakan langkah yang sangat menentukan. Langkah finalisasi ini berguna untuk menyempurnakan hasil rekaman, menambahkan suara latar (ambient sound), menambahkan efek suara, mengatur volume suara aktor yang mungkin masih fluktuatif, dan juga mengatur panjang atau durasi audiobook (trimming). Sebagian besar pekerjaan dalam langkah finalisasi ini dilakukan menggunakan perangkat lunak atau software seperti yang telah disampaikan di depan. Selain memodifikasi file hasil rekaman, fungsi finalisasi adalah untuk mengubah format file suara menjadi file yang dapat dimainkan pada sound player. Ada banyak variasi file suara yang dapat dipilih, mulai dari FLAC (Free Lossless Audio Codec) yang merupakan format file audio yang tidak mengalami pengurangan kualitas suara file. Namunkelemahan formatini adalah hasilfilenya yang besar sehingga tidak bersahabat bagi player yang memiliki kapasitas kecil. Pilihan lain yang paling umum dan paling banyak digunakan adalah format MP3. Format MP3 ini merupakan format file audio dengan kualitas audio yang dikompresi sampai 1/20 ukuran file aslinya. Hal ini menyebabkan file hasil konversi menjadi sangat kecil dan mudah ditransmisikan melalui jalur internet dan tidak memakan banyak waktu. Setelah proses finalisasi selesai, maka file hasilnya sudah bisa didistribusikan kepada para pengguna. File akhir inilah yang akan digunakan oleh parapendengar.

\subsection{Penggunaan audiobook sebagai alternative masatua}

Satua Bali merupakan salah satu media komunikasi dan penyampai pesan yang sangat 
efektif sekaligus merupakan cara yang sangat menyenangkan untuk memperkenalkan bahasa Bali dan melestarikan bahasa Bali sekaligus. Pada jaman dahulu, satua Bali merupakan bagian dari repertoire kemampuan orang tua, sementara masatua adalah sebuah kegiatan yang sudah hamper seperti ritual yang dilakukan oleh orang tua, dengan berbagai fungsinya, mulai dari memberikan nasihat kepada anak, memberikan peringatan atau perhatian terhadap tingkah laku anak, sampai untuk menghibur anak-anak sebelum tidur. Sampai saat ini, satua dan masatua masih digunakan secara aktif di rumah tangga oleh para orang tua, seperti yang ditemukan oleh Suastika, di desa desa di kabupaten Bali, provinsi Bali (Suastika:2011). Selain digunakan di rumah, satua juga banyak digunakan di sekolah, terutama selama proses pembelajaran mata pelajaran Pendidikan Bahasa Bali dan Pendidikan Agama Hindu di dekolah-sekolah di Bali (Karsa: 2006; Pramayanti: 2012).

Satua Bali sendiri merupakan media yang sangat efektif untuk memaparkan bahasa Bali kepada anak-anak Bali di usia dini. Anak-anak perlu dikenalkan dengan bahasa daerahnya semenjak usia dini, sehingga anak memahami bahwa bahasa daerahnya berperan dalam kehidupannya. Demikian pula dalam kegiatan sehari-hari, anak-anak perlu dilibatkan dalam percakapan sehari-hari dengan menggunakan bahasa daerahnya. Menurut Johnson (1989) usia dimana seorang anak terpapar sebuah bahasa memiliki pengaruh terhadap penguasaan sang anak terhadap bahasa dimaksud. Lebih jauh lagi, Perani (2003) melaporkan temuannya bahwa anak-anak yang terpapar bahasabahasa pada usia 3 tahun kebawah, menunjukkan aktivitas otak yang serupa dengan saat otak sedang mempelajari sebuah bahasa asli oleh si pembelajar. Hal ini berarti bahwa usia anak dibawah 3 tahun adalah saat yang tepat untuk mulai mengenalkan bahasa-bahasa kepada sang anak (Perani, 2003).
Selain Johnson dan Perani, Ioulia Kouvelman dan Laura-Ann Petito pada 2008 melakukan penelitian mengenai pengaruh usia terpapar bahasa dengan penguasaan bahasa tersebut pada anak-anak. Kouvelman melakukan penelitian terhadap sekelompok anak yang mempelajari bahasa Spanyol dan bahasa Inggris. Hasil penelitian Kouvelman dan Petito menunjukkan bahwa terdapat hubungan antara usia terpapar bahasa dan kemampuan anak berbahasa. Lebih lanjut, mereka menemukan bahwa anak yang terpapar bahasa pada usia dibawah 3 tahun memiliki kemampuan berbahasa yang lebih baik daripada anak yang terpapar bahasa pada usia 3 sampai 5 tahun (Kouvelman dan Pettito, 2008).

Dari hasil penelitian-penelitian diatas dapat kita simpulkan bahwa usia memang memiliki hubungan dengan penguasaan bahasa, yang berarti orang tua sebaiknya memperkenalkan bahasa kepada anak sejak usia muda. Disini audiobook berperan penting membantu orang tua dalam memperkenalkan bahasa kepada anak. Untuk menjamin tercapainya keberhasilan pemutaran audiobook ada beberapa hal yang harus dipehatikan. Harmer (2007) menjelaskan bahwa ada enam hal yang harus diperhatikan dalam menyampaikan materi audioyaitu:

1) Pemahaman teknis.

Bagian tak terpisahkan dari audiobook adalah pemutar audiobook itu sendiri. Tentunya keberhasilan pemutaran audiobook sangat tergantung pada kemampuan menggunakan pemutar audiobook tersebut. Pada era 1970 audiobook hanya dapat diputar pada alat pemutar kaset yang besar dan berat, namun hari ini, bahkan telepon seluler paling murahun telah dilengkapi dengan aplikasi pemutar suara. Orang tua hanya perlu membiasakan diri pada pengoperasian alat atau aplikasitersebut. 
2) Persiapan yangbaik

Orang tua da anak perlu bersiap untuk mendengarkan audiobook yang akan diputar, orang tua perlu menyiapkan diri dengan memilih audiobook yang tepat. Di sisi lain anak juga harus siap untuk berdiskusi mengenai audiobook yang telah ia dengarkan.

3) Tidak cukup hanya sekali

Audiobook sebaiknya tidak hanya diputar sekali, karena pemutaran sekali hanya akan membatasi informasi yang diterima anak. Inilah sebabnya, sebuah audiobook tidak boleh terlalu panjang durasinya, agar tidak membosankan untuk anak.

4) Anak harus dikondisikan untuk menggunakan bahasa yang didengarkan

Setelah pemutaran audiobook, orang tua dan anak harus berinteraksi mendiskusikan mengenai audiobook yang baru mereka dengarkan. Dalam diskusi ini orang tua harus berperan aktif membentuk, merangsang, dan mendorong anak untuk berbicara dengan bahasa Bali, agar kemampuan bahasa mereka dapat diaktifkan.

5) Perbedaan umur dan perbedaan tugas.

Kegiatan pasca mendengarkan wajib dilakukan, namun bentuk kegiatannya tidaklah harus sama antara anak berbeda usia. Orang tua bisa memilih berbagai kegiatan, mulai menjawab pertanyaan dengan singkat, menemukan informasi spesifik, merangkun cerita, sampai menceritakan kembali satua yang telah didengar anak. Seiring peningkatan kemampuan anak, maka beban tugasnyapun harus ditingkatkan.

6) Eksploitasi materi sepenuhnya

Orang tua harus berusaha membuat materi satua menjadi ladang informasi yang bisa dioptimalkan dengan membuat sebanyak mungkin variasi kegiatan pasca mendengarkan. Hal ini akan menantang anak dan juga membuat kegiatan mendengarkan audiobook menjadi tidak membosankan (Harmer, 2007: 96-100).

Lebih jauh lagi, dalam menggunakan audiobooksatua Bali, ada langkah-langkah dan parameter yang harus dipenuhi. Dalam penggunaan audiobook setidaknya ada tiga langkah yang harus diperhatikan, yang dibagi menjadi pra mendengarkan, mendengarkan, pasca mendengarkan. Langkah pra mendengarkan bertujuan untuk memberikan konteks dari isi atau topik satua yang akan didengarkan anak di audiobook. Hal ini bertujuan agar anak nantinya dapat menghubungkan antra kehidupannya sehari-hari dengan materi satua yang akan didengarkan. Misalnya orang tua akan memberikan satua tentang karakter kejujuran, maka orang tua perlu memberi pengantar tentang nilai-nilai kejujuran yang nantinya akan dituturkan dalam satua. Hal ini bertujuan untuk membantu anak mendapatkan pengetahuan awal yang nantinya bisa mereka hubungkan dengan isi satua yang mereka dengar.

Langkah mendengarkan merupakan langkah penting selanjutnya. Dalam langkah ini keterlibatan orang tua adalah mutlak. Orang tua harus hadir secara fisik dan mendampingi anakanak saat mendengarkan audiobook. Orang tua juga harus aktif untuk mengoperasikan audio player, untuk memenuhi kebutuhan anak, seperti misalnya mempause, menghentikan, menyalakan atau merewind bagian yang ingin didengar oleh siswa. Selain itu, tugas orangtua pada langkah ini adlah untuk membantu anakanak dalam memahami kata-kata atau idiom yang sulit.

Langkah terakhir namun tidak kalah pentingnya dengan langkah sebelumnya adalah langkah Pasca mendengarkan. Dalam langkah ini, orang tua berperan merangsang anak untuk menggunakan bahasa Bali dalam diskusi tentang satua yang baru didengarnya. Dalam langkah ini, orang tua harus aktif bertanya kepada anak, 
menanyakan isi cerita, amanat dari cerita yang diapat siswa, serta persepsi siswa terhadap isi cerita, dan kegiatan mendengarkan audiobook itu sendiri. Namun yang perlu diingat adalah bahwa kegiatan harus dimulai dari kegiatan sederhana dan perlahan berkembang menjadi semakin kompleks. Orang tua bisa mulai dari pertanyaan sederhana dengan jawaban ya dan tidak, kemudian melangkah pada jawaban pendek untuk informasi spesifik, kemudian menyampaikan gambaran umum cerita, dan terakhir bisa sampai pada kegiatan menceritakan kembali isi satua dengan bahasa mereka sendiri.

Dengan langkah-langkah ini, orang tua akan bisa memapar anak dengan bahasa Bali semenjak usia dini, dengan kegiatan yang menyenangkan dan menarik untuk anak. Satua Bali sarat dengan nilai-nilai pendidikan yang dapat digunakan untuk mengajarkan etika kepada masyarakat. Dengan pengalaman nilainilai yang terdapat dalam satua Bali, seseorang diharapkan mampu menjadi pribadi yang berbudi pekerti luhur dan mempunyai karakter. Dengan memberikan bimbingan secara tidak langsung melalui satua maka, watak, mental, sikap, dan tingkah laku anak itu akan terbentuk menjadi karakter yang baik. Aspek nilai satua itu sangat tinggi dan berguna. Sastra dalam bentuk satua merupakan cermin kehidupan. Bagaikan sebuah cermin satua dapat memantulkan berbagai hal positif yang muncul dari dalamnya.

Selain mampu membawa nilai-nilai budaya yang baik, satuaBali mewakili tidak saja budaya Bali namun juga konsep-konsep teologi Hindu (Suastika, 2001; Mahardika, 2013). Hal ini berarti, pengembangan karakter yang terdapat dalam satua bali, secara tidak langsung akan mengajarkan konsep-konsep teologi Hindu. Selain itu, kegiatan ini juga menghadirkan orang tua dalam konteks memberikan pengetahuan dan membimbing anak secara intensif. Hubungan orang tua dan anak ini akan sangat membekas untuk anak dan membangun kedekatan emosional antara anak dan orang tua.

\section{Simpulan}

Berdasarkan penjelasan diatas, dapat disimpulkan bahwa audiobook dapat menjadi alternatif yang baik untuk membangkitkan kembali budaya masatua Bali untuk memapar anak dengan bahasa Bali semenjak usia dini. Dengan paparan usia dini, diharapkan anak akan dapat menguasai bahasa Bali secara lebih baik. Penggunaan audiobook satua Bali perlu mengikuti enam prinsip penggunaan materi audio dari Harmer dan juga mengikuti 3 langkah pemberian materi audio yaitu langkah pra mendengar, mendengar dan pasca mendengar.

\section{Daftar Pustaka}

American Foundation for the Blind. 2016. Talking Books for People Who Are Blind or Visually Impaired. Tersedia pada http:/ /www.afb.org/info/living-with-vision-loss/ using-technology/reading-and-writing/ talking-books-933/1235 diakses pada 18 Januari 2017 pukul 15:30.

Dale, Edgar. 1969. Audio-Visual Methods in Teaching, 3rd ed. New York: Holt, Rinehart \& Winston.

Dwijayanti, Sang Ayu. 2016. Campur Kode Bahasa Bali Ri Sajeroning Seni Bebalihan Tektok Ring Puri Kantor Kecamatan Ubud Kbupaten Gianyar. Skripsi tidak diterbitkan. Denpasar: IHDN Denpasar.

Goldsmith, F. 2002. Earphone English. Library Journals Archives. tersedia padahttp:// lj.libraryjournal.com/2002/05/ljarchives/ earphone-english diakses pada 17 Januari 2017 pukul 15:35

Harmer, Jeremy. 2007. How to Teach English. Malaysia. Longman

Johnson, J., \& Newport, E. (1989). Critical period effects in second language leaning: 
The influence of maturational state on the acquisition of English as a second language. Cognitive Psychology, 21, 60-99. http:// faculty.ucmerced.edu/khakuta/research/ publications / $(2001) \% 20-$ $\% 20 \mathrm{~A} \% 20 \mathrm{CRITICAL} \% 20 \mathrm{PERIOD} \%$ ACQUISITION.pdf

20FOR\%20SECOND\%20LANGUAGE\%20

Karsa, I Wayan. 2006. Satua Sebagai Media Pendidikan Agama Hindu Pada Lingkungan Keluarga Di Desa Sekardadi, Kecamatan Kintamani, Kabupaten Bangli. Thesis. Denpasar: IHDN Denpasar.

Kovelman I., Baker, A.S., \& Pettito L. (2008). "Age of First Bilingual Exposure as A New Window into Bilingual Reading Development". http://www.utsc.utoronto. ca/ petitto/BLC2008.pdf

Mahardika, IGNA Wijaya. 2013. "Satua Bali and Character Education an Old Way for a New Approach". Dalam Suwardi Endraswara, dkk. (Ed.) Folklore Dan Folklife Dalam Kehidupan Modern. (hlm. 354-361) Yogyakarta: Penerbit Ombak.

Pramayanti, Sri. 2012. Cerita Tantri Nandaka Harana sebagai media pendidikan agama hindu Di SMAN 1 Selat Kabupaten Karangasem. Thesis. Denpasar. IHDN Denpasar.

Perani, D.,Abutalebi, J., Paulesu, E., Brambati, S., Scifo, P. \& Cappa, S. F. (2003). The role of age of acquisition and language usage in early, high-proficient bilinguals: 
An fMRI study during verbal fluency. Human Brain Mapping,19 (3), 170-182.

Sidi, I Wayan Eka Purnama. 2014. Utsaha Ngalestariang Basa Bali Ring ParaYowana Malarapan Antuk Sekaa Santi Githa Saraswasti Desa Tingkadbatu Kecamatan Tembuku Kabupaten Bangli. Skripsi tidak diterbitkan. Denpasar: IHDN Denpasar.

Suarjana, Putra I Nyoman. 2007. Sor Singgih Basa Bali Ke-Bali-an Manusia Bali Dalam Dharma Pepadikan, Pidarta, Sambrama Wacana dan Dharma Wacana. Denpasar : Pt TohpatiGrafika Utama.

Suastika, I Made. 2011. Tradisi Sastra Lisan (satua) di Bali, Kajian Bentuk Fungsi, dan Makna. Denpasar. Pustaka Larasan.

Suwandayani, Ni Putu Ayu. 2015. International Baligraphy Festival Pinaka Panglimbak aksara Bali ring Dura Negara. Skripsi tidak diterbitkan. Denpasar: IHDN Denpasar.

Welyantari, Ni Luh. 2016. Campur Kode Sajeroning Babaosan Ring Jejaring Social (BBM). Skripsi tidak diterbitkan. Denpasar: IHDNDenpasar.

Ozgur, Ziya A. \& Gurcan, Ibrahim H. 2004. AnAudio-Book Project for Blind Students at the Open Education System of Anadolu University. The Turkish Online Journal of Education Technology. Tersedia pada ww w.tojet.net/articles/v 3 i $3 /$ 331.pdfdiakses pada 20 Januari 2017 pukul 09:00: 